\title{
Multiple variations in the course and motor branching pattern of the musculocutaneous nerve with unusual communication with the median nerve
}

\author{
V. Chentanez, P. Jaruprat, P. Udomchaisakul, S. Agthong, T. Huanmanop \\ Department of Anatomy, Faculty of Medicine, King Chulalongkorn Memorial Hospital, \\ Chulalongkorn University, Bangkok, Thailand
}

[Received: 27 November 2015; Accepted: 10 February 2016]

\begin{abstract}
Anatomic variations in course and motor branching pattern of the musculocutaneous nerve (MCN) with unusual communication with the median nerve were determined on the left arm of a 62-year-old formalin fixed male cadaver. The MCN did not pierce the coracobrachialis muscle. It provided 4 primary motor branches. The first branch emerged $1.5 \mathrm{~cm}$ inferior to the coracoid process to innervate the coracobrachialis muscle. The second branch emerged $8 \mathrm{~cm}$ inferior to the coracoid process to innervate the biceps brachii muscle. The third branch to brachialis muscle emerged $13.9 \mathrm{~cm}$ inferior to the coracoid process. The last branch to the common belly of biceps brachii muscle emerged $19.6 \mathrm{~cm}$ inferior to the coracoid process. Two communications with the median nerve were observed. The proximal thick communicating branch had the direction from the MCN to the median nerve while the distal one was a small nerve bundle with a direction from the median nerve to the MCN. The present report provided evidence of multiple variations in one MCN which had not been reported previously. Anatomic variation in this case has clinical implications, considering that injury of the MCN in the upper part of arm would cause unexpected paralysis of flexor muscles of forearm and thenar muscle due to communications between this and median nerve. (Folia Morphol 2016; 75, 4: 555-559)
\end{abstract}

Key words: musculocutaneous nerve, median nerve, communicating branch, motor branch

\section{INTRODUCTION}

The musculocutaneous nerve (MCN) is one of the terminal branches of the brachial plexus. It derives from the lateral cord and receives fibres from $\mathrm{C} 5-\mathrm{C7}$ nerve roots. The classical pathway is the nerve exits the axilla by piercing the coracobrachialis muscle, and then lies between the biceps brachii and brachialis muscles while supplying these muscles and continues as the lateral antebrachial cutaneous nerve (LACN) in the forearm. Many authors have reported the variations of the origin and course of the MCN $[1,5,11$, $27,30]$. The variations ranged from complete absence $[2,4,10,12,22,25,26,31]$ to a double MCN [1]. Unusual branches of MCN originating from the median nerve $(\mathrm{MN})$ have been previously documented $[2,4$, $11,26,27]$. Several articles have described patterns of motor branching of the MCN $[7,9,15,18,19,23$, $24,34]$. Furthermore, the connection between the

Address for correspondence: Dr V. Chentanez, Department of Anatomy, Faculty of Medicine, King Chulalongkorn Memorial Hospital, Chulalongkorn University, Bangkok 10330, Thailand, tel: 662-860701084, e-mail: fmedvct@gmail.com 


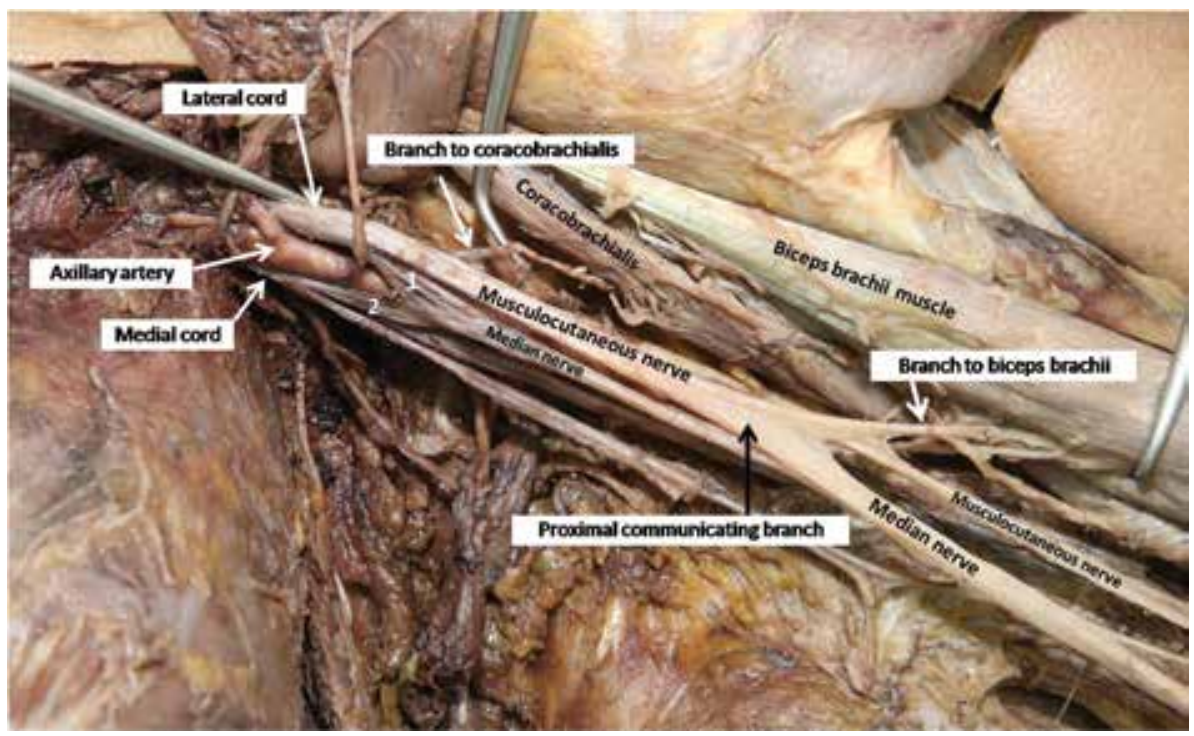

Figure 1. At the level of the coracoid process of the left arm, the lateral cord sent three small nerve bundles (1) to join the medial root of median nerve from the medial cord (2) to form the median nerve. The musculocutaneous nerve did not pierce the coracobrachialis muscle. It gave a muscular branch to innervate the coracobrachialis muscle and a thick communicating branch to the median nerve (proximal communicating branch). On the radial side of this communication, a muscular branch emerged to innervate each head of the biceps brachii muscle.

MCN and MN has been reported and classified by various criteria $[3,8,11,14,16,17,20,28,33]$. The $\mathrm{MN}$ is formed by the fusion of medial and lateral roots from the medial and lateral cords, respectively. It descends in the arm adjacent to brachial artery without any branch. However, the fusion of the lateral cord with the MN and an absence of the MCN have been documented [11, 31]. This knowledge is clinically significant for nerve reconstructions, nerve transfer and neurectomy to relieve elbow flexor spasticity $[9,15,34]$. The aim of this study is to report a case of multiple variations both in the course and branching pattern of the MCN together with the communications with the MN.

\section{CASE REPORT}

During dissection of the brachial plexus of a 62-year-old formalin fixed male cadaver at laboratory of Anatomy, Faculty of Medicine, Chulalongkorn University, anatomic variations in the course and branching pattern of the MCN with unusual communications between the MN and MCN were determined on the left arm. The MCN of the right arm appeared to have a classical pattern. At the level of the coracoid process of the left arm, the lateral cord sent three small nerve bundles to join the medial root from the medial cord to form the MN (Fig. 1). The main trunk of the lateral cord became the MCN and did not pierce the coracobrachialis muscle. It gave a muscular branch to innervate the coracobrachialis muscle at a distance of $1.5 \mathrm{~cm}$ inferior to the coracoid process (Figs. 1, 2). The MCN passed down the arm until $6.5 \mathrm{~cm}$ inferior to the branch to the coracobrachialis muscle or $8 \mathrm{~cm}$ inferior to the coracoid process where it gave a thick communicating branch to the MN (Figs. 1, 2). On the radial side of this proximal communication, a muscular branch emerged and divided into two branches to innervate each head of the biceps brachii muscle (Fig. 2). At a distance of $5.5 \mathrm{~cm}$ distal to the branch to the biceps brachii muscle, a distal communicating branch ran obliquely from the MN to the MCN (Fig. 2). The MCN continued to the distal arm and gave a muscular branch at $5.9 \mathrm{~cm}$ inferior to branch to the biceps brachii muscle or $13.9 \mathrm{~cm}$ from the coracoid process which divided into two branches to supply the brachialis muscle (Fig. 2). Before terminating as the lateral antebrachial cutaneous nerve, the MCN gave another muscular branch to the common belly of biceps brachii muscle (Fig. 2). The exit point of this branch was $19.6 \mathrm{~cm}$ from the coracoid process.

\section{DISCUSSION}

The MCN variation has been classified by a four step algorithm proposed by Guerri-Guttenberg and Ingolotti [11]. The first step was to determine the presence (1) or absence (0) of the MCN. When the MCN 


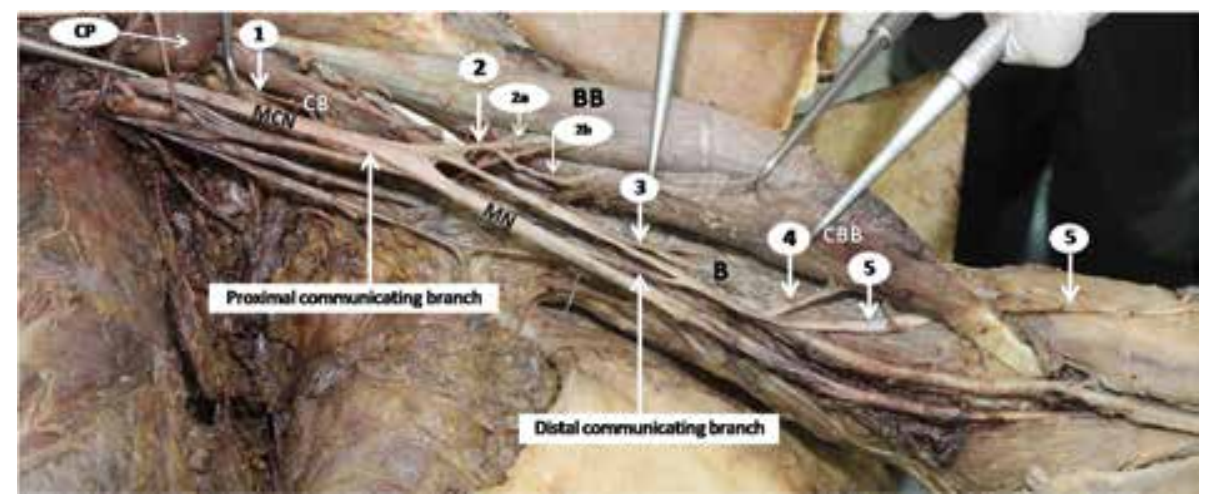

Figure 2. Four primary motor branches emerged from the musculocutaneous nerve (MCN): (1) branch to coracobrachialis muscle (CB), (2) branch to both heads of biceps brachii muscle (BB), (3) branch to brachialis muscle (B) and (4) branch to common belly of biceps brachii (CBB); (5) lateral antebrachial cutaneous nerve; $\mathrm{CP}$ - coracoid process; $\mathrm{MN}$ - median nerve.

was present, the second step was to determine if the MCN pierces the coracobrachialis muscle $(A=$ pierce, $B=$ not pierce). The third step was to determine the presence of communication between the MCN and $\mathrm{MN}$ or other variations based on the number of communication $(0,1$, and 2$)$, the fusion with the MN (3) and distal origin of the MCN (4). The fourth step was to determine the relationship of the communication with the port of entry to the coracobrachialis muscle. According to these criteria, the MCN in the present case could be classified as 1B2 without consideration of the direction of communication between the MCN and MN. Guerri-Guttenberg and Ingolotti [11], Kervancioglu et al. [15] and Pacha et al. [24] reported that $11.1 \%, 10 \%$ and $6.5 \%$ of MCN, respectively, did not pierce the coracobrachialis muscle. Recently, Troupis et al. [32] reported a case of complex brachial anatomic variation in which the MCN did not pierce the coracobrachialis muscle. Guerri-Guttenberg and Ingolotti in 2009 [11] proposed that this anatomic variation might have a protective function against trauma of flexion because of more flexibility. Moreover, Choi et al. [8] classified the communication between the MCN and MN into three patterns: complete fusion, one supplementary branch and two supplementary branches. The present case cannot be classified to any pattern. In addition, Maeda et al. [20] classified the communication between the MCN and MN into five types according to their directions and formation. The present case was similar to type B2b in which one communication arose from $\mathrm{MN}$ descended laterally and joined the $\mathrm{MCN}$ at the region between the branches to the brachilis and biceps brachii (Fig. 2). However, the difference was the occurrence of another thick communication lying proximally and the direction was from the $\mathrm{MCN}$ to MN (Fig. 2). This communication from the MCN to MN was not similar to any subtype of type $A$ [20]. Kaus and Wotowicz [14] reported two junctions of the MN and MCN similar to the present case but without an additional communicating branch from the $\mathrm{MN}$ to the MCN. Kirazli et al. [16] reported a case of MCN piercing the coracobrachialis muscle and terminating by giving a communicating branch to the MN. From this branch, the branches to the brachialis muscle and LACN were given. The MCN in the present case did not pierce the coracobrachialis muscle and there was an additional communicating branch from the MN to MCN. Taken together, the present communications between the MCN and MN observed in the left arm of this cadaver did not resemble any variations described previously $[3,8,14,16,17,20,28,33]$. In this case, injury of the $\mathrm{MCN}$ in the upper arm superior to the proximal communication may cause paralysis of the elbow flexor and unexpected paralysis of flexor and/or thenar muscles.

Cambon-Binder and Leclercq [9] reported that the biceps muscle was innervated by one to five primary motor branches while the brachialis muscle received one to three primary branches. In the present case, there were two primary motor branches to the biceps muscle and one primary motor branch to the brachialis muscle. Furthermore, Chiarapattanakom et al. [7] stated that the nerve to the brachialis muscle was always found distal to the nerve to the biceps brachii muscle but, in the present case, the branch to the common belly of the biceps brachii muscle was distal to the branch to brachialis muscle. Yang et al. [34] 
classified the variations in the innervation of the biceps brachii muscle into three types. The present case could be classified as type III which was found only in $8.3 \%$ of cases. The average distance between the two branches was $8.5 \mathrm{~cm}$ [34] but in the present case, it was $11.6 \mathrm{~cm}$.

The variations of the MCN and its communication with the MN may be explained by an embryological point of view. As described in Langman's medical embryology [29], as soon as the upper limb buds form, the ventral primary rami from the lower five cervical and upper two thoracic spinal nerves grow into the mesenchyme of the upper limb buds. When the muscle cells split into dorsal (extensor) and ventral (flexor) compartments, the nerves will also divide to form dorsal and ventral branches, and enter to the corresponding compartments. The combination of dorsal branches will become the radial nerve, whereas the combinations of ventral branches give rise to median and ulnar nerves. Iwata [13] had done an embryological study on the development of the brachial plexus and reported that the MCN was derived later from the MN. He also proposed that the presence of communicating branch might be the failure of differentiation of some nerve fibres in taking an aberrant cause. Several investigators had explained that the anatomical variation could be the result of developmental anomaly [6, 7, 25, 26]. In addition, from a comparative study, the existence of the connections between the MCN and MN might represent the primitive nerve supply of the anterior muscle of the arm [21].

\section{CONCLUSIONS}

In summary, this study reported a case of multiple variations in the course, motor branching pattern of the MCN and communication with the MN which has not been reported previously.

\section{Acknowledgements}

The authors wish to thank Miss Wullapa Katinsommitr for her assistance in taking the photographs.

\section{REFERENCES}

1. Abu-Hijleh MF (2005) Three headed biceps brachii muscle associated with duplicated musculocutaneous nerve. Clin Anat, 18: 376-379.

2. Aydin ME, Kale A, Edizer M, Kopuz C, Demir MT, Çorumlu U (2006) Absence of the musculocutaneous nerve together with unusual innervation of the median nerve. Folia Morphol, 65: 228-231.
3. Ballesteros LE, Foreero PL, Buitrago ER (2015) Communication between the musculocutaneous and median nerves in the arm: an anatomical study and clinical implications. Rev Bras Ortop, 50: 567-572 doi: 10.1016/j.rboe.2014.08.009.

4. Bhanu PS, Sankar KD (2012) Bilateral absence of musculocutaneous nerve with unusual branching pattern of lateral cord and median nerve of brachial plexus. Anat Cell Biol, 45: 207-210.

5. Bhattarai C, Poudel PP (2009) Unusual variation in musculocutaneous nerves in Nepalese. Kathmandu Univ Med J, 28:408-410.

6. Chauhan R, Roy TS (2002) Communication between median and musculocutaneous nerve: a case report. J Anat Soc Ind, 51: 72-75.

7. Chiarapattanakom $P$, Leechavengvongs $S$, Witoonchart $K$, Uerpairojkit C, Thuvasethakul P (1998) Anatomy and internal topography of the musculocutaneous nerve: the nerve to the biceps and brachialis muscle. J Hand Surg Am, 23: 250-255.

8. Choi $\mathrm{D}$, Rodriguez-Niedenführ M, Vázquez T, Parkin I, Sañudo JR (2002) Patterns of communications between the musculocutaneous and median nerves in the axilla and arm. Clin Anat, 15: 11-17.

9. Combon-Binder A, Leclercq C (2015) Anatomical study of the musculocutaneous nerve branching pattern: application for selective neurectomy in the treatment of elbow flexors spasticity. Surg Radiol Anat, 37: 341-348. doi: 10.1007/s00276-014-1371-x.

10. Fregnani JH, Macéa MI, Pereira CS, Barros MD, Macéa JR (2008) Absence of the musculocutaneous nerve: a rarebanatomical variation with possible clinical-surgical implication. Sao Paulo Med J, 126: 288-290.

11. Guerri-Guttenberg RA, Ingolotti M (2009) Classifying musculocutaneous nerve variations. Clin Anat, 22: 671-683.

12. Gumusburun E, Adiguzel E (2000) A variation of brachial plexus characterized by the absence of the musculocutaneous nerve: a case report. Surg Radiol Anat, 22: 63-65.

13. Iwata H (1960) Studies on the development of brachial plexus in Japanese embryo. Rep Dept Anat Mie Prefect Univ Sch Med, 13: 129-144.

14. Kaus M, Wotowicz Z (1995) Communication branch between the musculocutaneous and median nerve in human. Folia Morphol, 54: 273-277.

15. Kervancioglu P, Orhan M, Kilinc N (2011) Patterns of motor branching of the musculocutaneous nerve in human fetuses and clinical significance. Clin Anat, 24: 168-178.

16. Kirazli Ö, Tatarli N, Ceylan D, Hacioğlu H, Uygun S, Şeker A, Keleş E, Çavdar S (2013) A variation of the cords of the brachial plexus on the right and a communication between the musculocutaneous and median nerves on the left upper limb: a unique case. J Neurol Surg A Cent Eur Neurosurg, 74 (suppl. 1): e176-e179. doi: 1055/s-0032-1333416.

17. Kumar N, Guru A, D'Souza MR, Patil J, Nayak BS (2013) Incidences and clinical implications of communications between musculocutaneous nerve and median nerve in the arm-A cadaveric study. West Indian Med J, 62:744-747. doi: 107727/wimj2013.175.

18. Kwolczak-Mc Grath A, Kolesnik A, Ciszek B (2008) Anatomy of branches of the musculocutaneous nerve to the biceps and brachialis in human fetuses. Clin Anat, 21: 142-146. 
19. Lee JH, Kim HW, Im S, An X, Lee MS, Lee UY, Han SH (2010) Localization of motor entry points and terminal intramuscular nerve endings of the musculocutaneous nerve to biceps and brachialis muscles. Surg Radiol Anat, 32: 213-220. doi: 10.1007/s00276-009-0561-4.

20. Maeda S, Kawai K, Koizumi M, Ide J, Tokiyoshi A, Mizuta H, Kodama K (2009) Morphological study of the communication between the musculocutaneous and median nerves. Anat Sci Int, 84: 34-40. doi: 10.1007/s125-12565-008-0005-y.

21. Miller RA (1932) Comparative studies upon the morphology and distribution of the brachial plexus. Am J Anat, 54: 143-166.

22. Nakatani T, Tanaka S, Mizukami S (1997) Absence of the musculocutaneous nerve with innervation of coracobrachialis, biceps brachii, brachialis and the lateral border of the forearm by branches from the lateral cord of the brachial plexus. J Anat, 191: 459-460.

23. Oberlin C, Béal D, Leechavengvongs S, Salon A, Dauge MC, Sarcy JJ (1994) Nerve transfer to biceps muscle using a part of ulnar nerve for C5-C6 avulsion of brachial plexus: anatomical study and report of four cases. J Hand Surg Am, 19: 232-237.

24. Pacha Vicente D, Forcada Calvet $P$, Carrera Burgaya $A$, Llusá Pérez M (2005) Innervation of biceps brachii and brachialis: anatomical and surgical approach. Clin Anat, 18: 186-194.

25. Pacholczyk R, Klimek-Piotrowska Walocha JA (2011) Absence of the Musculocutaneous nerve associated with a supernumerary head of biceps brachii: a case report. Surg Radiol Anat, 33: 551-554. doi: 10.1007/s00276010-0771-9.
26. Parchand MP, Patil ST (2013) Absence of the musculocutaneous nerve with variations in course and distribution of the median nerve. Anat Sci. Int, 88: 58-60. doi: 10.1007/ s12565-011-0126-6.

27. Pontell M, Scali F, Marshall E (2011) A unique variation in the course of the musculocutaneous nerve. Clin Anat, 24: 968-970.

28. Radunovic M, Vukasanovic-Bozaric A, Radojevic N, Vukadinovic T (2013) A new anatomical variation of the musculocutaneous nerve and the median nerve anastomosis. Folia Morphol, 72: 176-179. Doi: 10.5603/ FM.2013.0030.

29. Sadler TW (2015) Langman's medical embryology. 13th Ed. Wolter Kluwer Health, 166-167.

30. Saeed M, Rufai AA (2003) Median and musculocutaneous nerves; Variant formation and distribution. Clin Anat, 16: 453-457.

31. Song WC, Jung HS, Kim HJ, Shin C, Lee BY, Koh KS (2003) $A$ variation of musculocutaneous nerve absent. Yonsei Med J, 44: 1110-1113.

32. Troupis Th, Michalinos A, Protogerou V, Mazarakis A, Skandalakis $P$ (2015) Complex anatomic variation in the brachial region. Folia Morphol, 74: 118-121. doi: 10.5603/ FM.2015.0015.

33. Venieratos D, Anagnostopoulou S (1998) Classification of communications between the musculocutaneous and median nerves. Clin Anat, 11: 327-331.

34. Yang ZX, Pho RWH, Kour AK, Med M, Pereira BP, Eng B (1995) The musculocutaneous nerve and its branches to the biceps and brachialis muscles. J Hand Surg Am, 20: 671-675. 